\title{
A QUESTÃO DA INOVAÇÃo EM FÁRMACOS NO BRASIL: PROPOSTA DE CRIAÇÃO DO PROGRAMA NACIONAL DE FÁRMACOS (PRONFAR)
}

\author{
Eliezer J. Barreiro* e Carlos Alberto Manssour Fraga \\ Departamento de Fármacos, Faculdade de Farmácia, Universidade Federal do Rio de Janeiro, CP 68006,
} 21944-971 Rio de Janeiro - RJ

\begin{abstract}
THE QUESTION OF INNOVATIVE DRUGS IN BRAZIL: THE PROPOSAL OF THE PRONFAR CREATION. Medicines are essential instruments to the preservation, maintenance and promotion of Health. The access to the medicine represents an important factor of social inclusion, depending on the availability of the pharmaceutical - active principle contained in the medicine that in $85 \%$ of the cases has a synthetic origin. In this scenario the importance of knowing how to make pharmaceuticals and medicines plays a significant role for the viability of the autonomous Health politics necessary for the demands of the major Nations. In this context, this work describes concisely the main aspects involved in the interdisciplinary drug discovery process, identifying the possible gorges for the successful development of innovative drugs in Brazil.
\end{abstract}

Keywords: Pronfar creation; innovative drugs in Brazil.

\section{PREÂMBULO}

A questão dos fármacos no País assume relevância inusitada quando eleita como parte integrante da política industrial, como o foi em meados do ano passado. Afinal foi reconhecido, de fato, que os fármacos e os medicamentos são instrumentos imprescindíveis à assistência farmacêutica, eficiente e segura à população. Portanto, fármacos e medicamentos são instrumentos essenciais de inclusão social, necessários à plena soberania da Nação.

Neste trabalho pretendemos abordar, ainda que de forma sumária, pois a complexidade do tema exigiria espaço superior ao de um mero artigo, aspectos relacionados à inovação em fármacos e o processo interdisciplinar envolvido, identificando possíveis gargalos e apresentando proposta de criação de um Programa Nacional de Fármacos (PRONFAR) preenchendo lacunas estratégicas pendentes nas diferentes propostas existentes, que comprometem o alcance de soluções efetivas para a inaceitável dependência externa nesta questão de interesse nacional.

\section{INTRODUÇÃO}

As dificuldades específicas da área de Fármacos e Medicamentos no País têm início, dentre suas possíveis razões históricas, na época em que a nova realidade da indústria farmacêutica chega ao Brasil, contribuindo para a substituição das boticas - onde se dispensavam medicamentos, em grande parte, manipulados - pelas primeiras farmácias comerciais que não mais formulam e passam a vender medicamentos industrializados.

O País consolida sua atividade industrial farmacêutica com as empresas multinacionais instalando-se aqui e passando a realizar apenas a quarta etapa da cadeia industrial farmacêutica, i.e. transformar o fármaco - princípio ativo do medicamento, ou insumo farmoquímico (desenvolvido fora e importado) - em medicamento, através da implantação da formulação galênica, e o necessário controle de qualidade dos medicamentos acabados, de fármacos e outros insumos necessários à produção farmacêutica.

Com esta configuração não é surpreendente que tenha ocorrido um significativo desenvolvimento assimétrico das Ciências Farmacêuticas no Brasil, onde a inovação foi subtraída consolidando-

*e-mail: ejb@pharma.ufrj.br se os métodos analíticos aplicados ao controle de qualidade de fármacos e medicamentos. Por outro lado, a indústria nacional, eminentemente de caráter familiar, passa a se dedicar majoritariamente aos medicamentos similares ou aqueles de fórmulas licenciadas, não havendo nenhuma perspectiva de inovação, embora novas associações farmacêuticas tenham sido criadas. Em termos acadêmicos, realiza-se, em 1968, a reforma universitária que provoca o enfraquecimento das instituições de ensino farmacêutico, restritas ao sistema público, federal ou estadual, à época, e onde se desenvolvem pesquisas na infância de nosso, hoje invejável, sistema de pós-graduação. Com a reforma e a criação dos institutos básicos, as Faculdades de Farmácia se vêem esvaziadas da maioria de seus principais grupos de pesquisa. Aquelas poucas que mantiveram a estrutura de disciplinas básicas junto, fisicamente, ao ensino profissional, observaram uma evolução científica muito superior às outras que não adotaram esta configuração. Com a perda da maioria de seus grupos de pesquisa e da competência científica que representavam, reduziu-se enormemente a capacidade de pesquisa em Fármacos e Medicamentos, nas casas de Ensino Farmacêutico. Perdem-se, então, as vocações específicas do profissional farmacêutico para com o Fármaco e o Medicamento e amplia-se o âmbito profissional para outros focos, reduzindo-se, praticamente, sua atuação nos Fármacos e Medicamentos às atividades de controle de qualidade.

Nestas circunstâncias, não se criaram as condições capazes de favorecerem a consolidação das atividades de pesquisa científica em Fármacos e Medicamentos nas instituições de ensino farmacêutico do País, que alijadas, continuadamente sob alegação de "não-enquadramento" aos editais públicos emitidos pelos órgãos de fomento governamentais, vêem sua capacidade de captar recursos praticamente eliminadas. Sem nunca ter havido algum programa especial de fomento (e.g. PADCT) voltado às Ciências Farmacêuticas, estas não acompanharam a evolução e o contínuo crescimento de outras áreas, especialmente no que se refere à maioria das disciplinas vinculadas à inovação farmacêutica (e.g. Química Medicinal e Química Farmacêutica), assimetrizando-se no âmbito do sistema nacional de pós-graduação.

\section{O PROCESSO DE INOVAÇÂO EM FÁRMACOS}

A descoberta de novas entidades químicas (NEQ), candidatas 
a novos fármacos, compreende uma cadeia complexa que para ser efetiva precisa estar bem articulada. A série de distintas etapas envolvidas, consecutivas ou não, que visam a descoberta de novas substâncias bioativas passíveis de representarem autênticas entidades químicas inovadoras de possível aplicação terapêutica, em suma define a inovação farmacêutica, pedra-de-toque da indústria farmacêutica (IF) que realiza pesquisa inovadora em fármacos ${ }^{1}$.

Uma visão sucinta da evolução cronológica do processo de descoberta de fármacos está ilustrada na Figura 1.

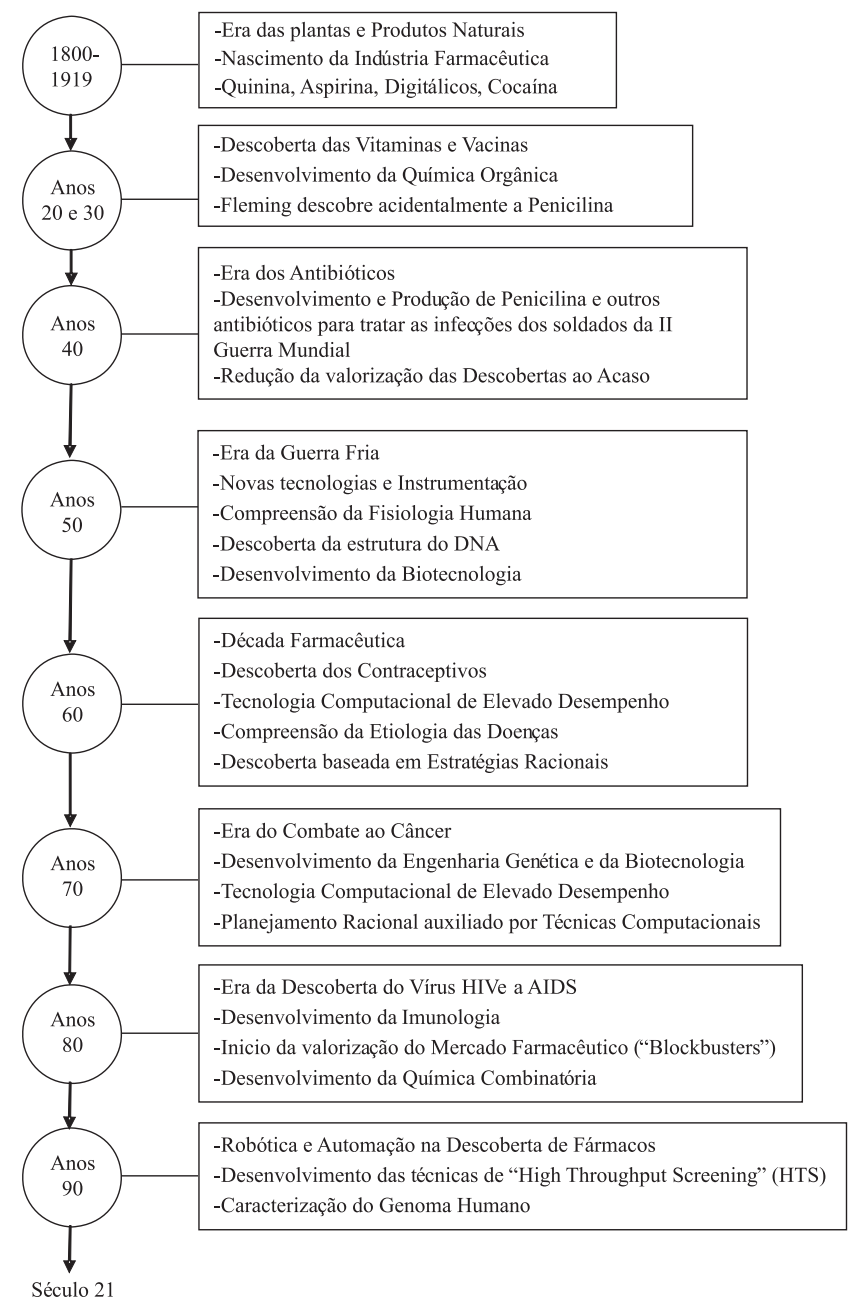

Figura 1. Cronologia do processo de descoberta de fármacos

Pode-se constatar que as descobertas de fármacos ocorreram, em determinados momentos, como fruto do acaso ou baseadas no uso de determinados produtos naturais, em geral de origem vegetal, e foram, gradualmente, substituídas por estratégias racionais que se fundamentam na estrutura do biorreceptor eleito como alvoterapêutico (biomacromolécula) ou em modificações moleculares planejadas na estrutura do ligante natural (micromolécula) ${ }^{2}$.

\section{O acaso na inovação em fármacos}

Vários fármacos disponíveis no mercado contemporâneo foram descobertos ao acaso ou intuitivamente ${ }^{3}$, através de observações inesperadas de fatos do dia-a-dia ou em etapas de triagem clínica.

A descoberta da penicilina (1), por Alexander Fleming em 1928, é um exemplo emblemático quando consideramos que a partir de então nasce a antibióticoterapia, com impacto fabuloso na qualida- de de vida da humanidade. Sua descoberta se dá após Fleming, um médico escocês que trabalhava em microbiologia no Hospital St. Mary, em King Cross, Londres, evidenciar a inibição do crescimento de cepas de Staphillococcus em uma placa de cultura esquecida em seu laboratório, com posterior identificação de contaminação por fungos do gênero Penicillium. Esta observação perspicaz viabilizou a antibióticoterapia ${ }^{4}$. Se o acaso tem um exemplo histórico datando do início do século 20, décadas após observa-se um segundo exemplo na Inglaterra. Desta feita, refere-se à descoberta do sildenafil (2), fármaco originalmente planejado por Campbell e colaboradores ${ }^{5}$ como anti-hipertensivo e antianginal que, em função da baixa eficácia terapêutica dos efeitos cardiovasculares observados, acaba desenvolvido para tratamento da disfunção erétil através de um novo mecanismo farmacológico, a partir da constatação de efeito colateral evidenciado na etapa inicial dos ensaios de triagem clínica ${ }^{5}$.<smiles>CC1(C)S[C@@H]2C(NC(=O)Cc3ccccc3)C(=O)N2C1C(=O)O</smiles><smiles>CCCc1nn(C)c2c(=O)[nH]c(-c3cc(S(=O)(=O)N4CCN(C)CC4)ccc3OCC)nc12</smiles>

Figura 2. Exemplos de fármacos descobertos ao acaso

\section{O "screening” randômico na inovação em fármacos}

Dentre os primeiros exemplos de fármacos descobertos através desta estratégia temos o prontosil (3), que foi descoberto por Domagk, em 1935, como apresentando importantes propriedades antibacterianas in vivo e que foram, mais tarde, identificadas como sendo dependentes do processo de bioativação metabólica que levava à formação da sulfanilamida (4), substância protótipo da família das sulfas antibacterianas ${ }^{6}$ (Figura 3).

Um segundo exemplo mais recente dá-se no âmbito de um programa de pesquisas conjunto do Instituto Nacional do Câncer (NCI) e o Departamento de Agricultura dos EUA, visando a identificação de novas substâncias terapeuticamente úteis no tratamento do câncer. Este programa é um exemplo significativo de como o fomento governamental à pesquisa inovadora em fármacos pode resultar em sucesso ${ }^{7}$. Em 1962, nos laboratórios do Research Triangle Park, chefiados por Wall, foi caracterizado o perfil antitumoral do extrato das cascas de Taxus brevifolia ${ }^{8}$. Na sequiência, a equipe de Wall e Wani ${ }^{9}$ logrou identificar o princípio ativo responsável por este efeito, chegando à estrutura do paclitaxel $\left(\right.$ Taxol $\left.^{\circledR}, 5\right)$, derivado diterpênico de biossíntese mista, com arquitetura molecular complexa e original ${ }^{10}$ (Figura 3).
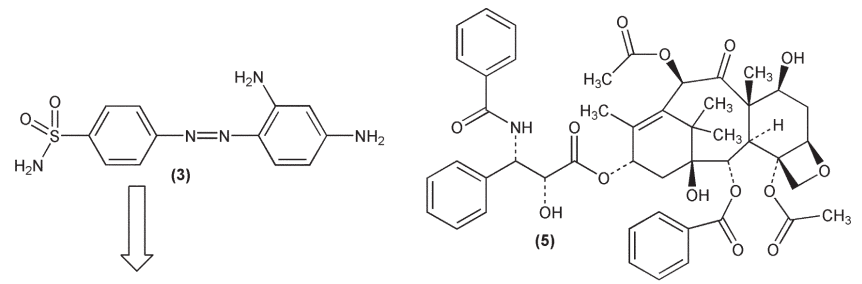<smiles>Nc1ccc(S(N)(=O)=O)cc1</smiles>

Figura 3. Exemplos de fármacos descobertos através de "screening" das propriedades farmacológicas

Mais recentemente, o "screening" randômico de quimiotecas representa uma versão moderna desta estratégia adotada pela in- 
dústria farmacêutica, que faz pesquisa, após a evolução da química combinatória e o advento de métodos robotizados de avaliação da afinidade de coleções de candidatos de ligantes de alvos macromoleculares ${ }^{11}$ (e.g. "HTS, high throughput screening").

\section{A estratégia de modificação estrutural de fármacos conhecidos}

O método de descoberta de fármacos baseado na modificação estrutural de fármacos conhecidos leva à identificação de novos compostos-protótipos que atuam pelo mecanismo farmacológico do primeiro, sendo denominados de fármacos "me-too"12. Podemos considerar como fármaco "me-too" aquele que é estruturalmente muito similar a um fármaco conhecido, com pequenas diferenças farmacoterapêuticas ${ }^{13}$. Esta estratégia é largamente empregada na IF que pesquisa novos fármacos sendo considerada, por alguns autores, como responsável por inovações parciais.

Dentre os numerosíssimos exemplos de fármacos desenvolvidos como "me-too" ${ }^{14}$, podemos mencionar a ranitidina ${ }^{15}(\mathbf{9})$, derivado furânico desenhado molecularmente através de modificações bioisostéricas do anel imidazólico e do grupamento funcional cianoguanidina do protótipo cimetidina ${ }^{16}(\mathbf{8})$, que foi o primeiro fármaco a ultrapassar a barreira de vendas de US\$ 1 bilhão de dólares/ano (EUA, 1986) ${ }^{17}$. As modificações estruturais efetuadas na ranitidina $(9)$, em relação à cimetidina $(8)^{18}$, resultaram em aumento da potência e maior seletividade pelo sub-tipo 2 de receptores histaminérgicos, alvo-terapêutico de ambos os fármacos antiúlcera $^{16}$ (Figura 4). Adicionalmente, podemos mencionar o pindolol $^{19}(7)$, estruturalmente planejado pela troca bioisostérica ${ }^{20}$ do anel naftaleno do protótipo propranolol ${ }^{21}$ (6), antagonista seletivo de receptores $\beta$-adrenérgicos, por um núcleo indólico contendo os mesmos 10 elétrons $\pi$ (Figura 4).

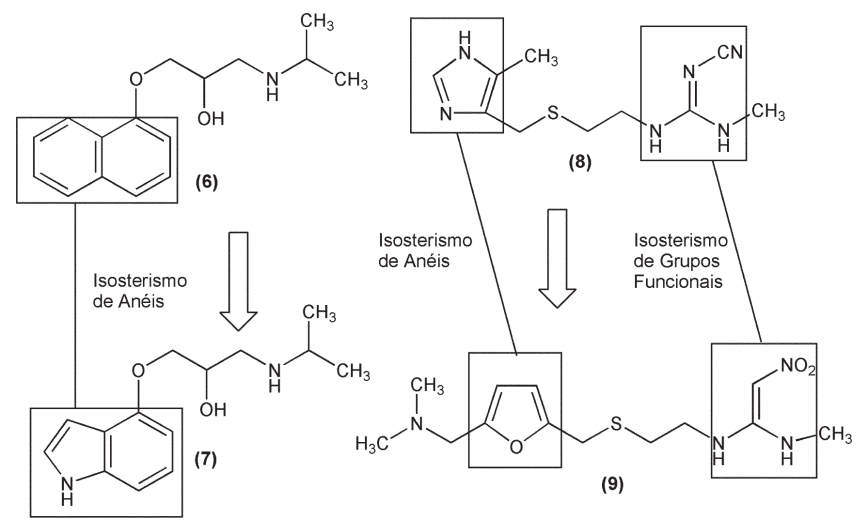

Figura 4. Exemplos de fármacos "me-too" descobertos através de modificações moleculares dos protótipos correspondentes

\section{A abordagem fisiológica como estratégia na inovação em fármacos}

O processo moderno de planejamento estrutural de novos fármacos, baseado no mecanismo farmacológico envolvido no processo fisiopatológico, representa importante estratégia para inovação radical em fármacos, e.g. cimetidina $^{22}(\mathbf{8})$ e captopril ${ }^{23}(\mathbf{1 0})$ (Figura 5), e tem sido referido na literatura como abordagem fisiológica que, por ser o de maior sucesso até o momento, será minuciosamente tratada a seguir.

Este processo inicia-se pela escolha correta do alvo-terapêutico relacionado à patologia que se pretende tratar, passa por posterior validação terapêutica e pela identificação ou descoberta de novos<smiles>CNC(=NC#N)NCCSCc1nc[nH]c1C</smiles>

(8)<smiles>O=C(O)C1CCCN1C(=O)CCS</smiles>

(10)
Figura 5. Exemplos de fármacos descobertos com base no mecanismo de ação

padrões moleculares de substâncias que representem autênticas entidades químicas originais, i.e., novas e inovadoras ${ }^{24}$, capazes de serem reconhecidas de forma eficiente - i.e., com níveis adequados de seletividade - pelos alvos-terapêuticos eleitos, promovendo resposta biológica, i.e., efeito terapêutico, de preferência por administração oral e com o menor índice de toxicidade possível (Figura 6).

A eleição do alvo-terapêutico é a etapa crítica no sucesso desta estratégia e depende estreitamente dos conhecimentos bioquímicos sobre a fisiopatologia da doença em estudo e seus mecanismos farmacológicos. Desta forma, identifica-se a localização celular e biológica do alvo-terapêutico, e.g. intra- ou extra-celular. O nível de conhecimento estrutural que se possa ter sobre este alvo orientará, em parte, a adoção da melhor estratégia de planejamento ou desenho estrutural dos novos padrões moleculares que serão investigados, visando a descoberta de novos candidatos a fármacos para tratamento daquela enfermidade ${ }^{25}$.

A Figura 6 ilustra, de maneira esquemática, as etapas envolvidas neste processo e evidencia o grau de complexidade e interdisciplinaridade que o caracterizam.

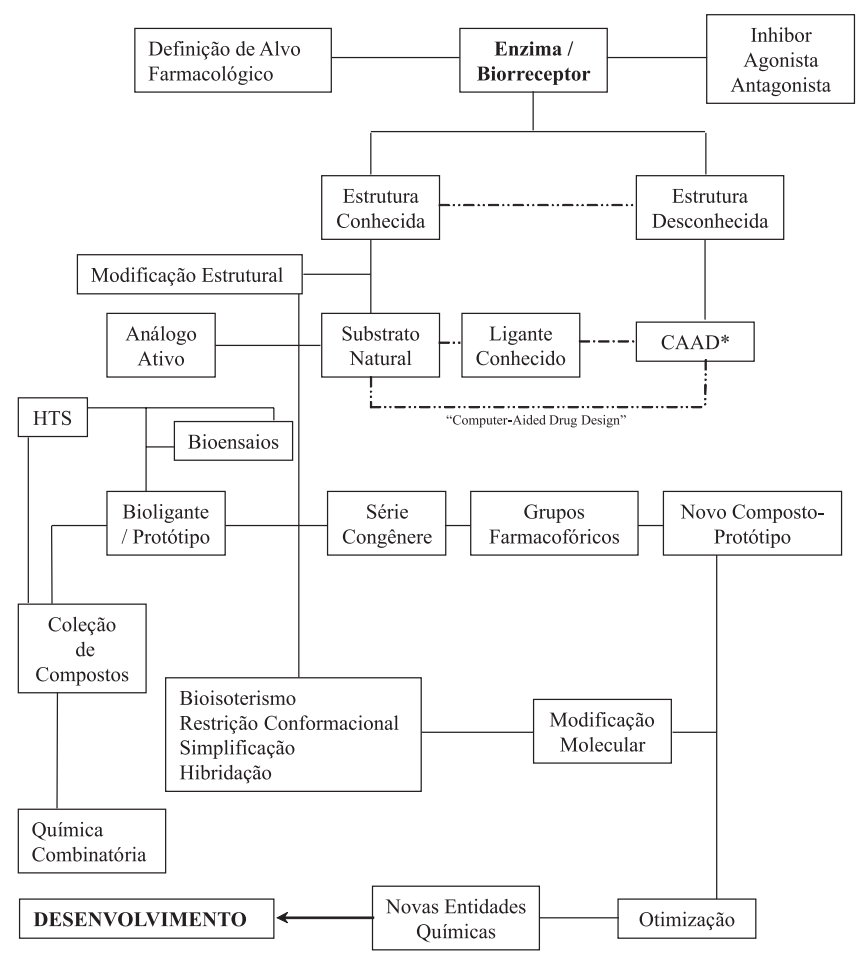

Figura 6. Estratégias empregadas na identificação de um novo compostoprotótipo com base na abordagem fisiológica

A integração do conhecimento científico próprio de diversas disciplinas é que contribui para a correta identificação do melhor alvo-terapêutico a ser eleito para tratamento, prevenção ou cura de uma fisiopatologia determinada, o que caracteriza a abordagem fisiológica ${ }^{25,26}$.

O planejamento e o desenho estrutural de novos padrões 
moleculares de substâncias que possuam propriedades farmacoterapêuticas úteis, capazes de representarem novos compostos-protótipos de fármacos, são tarefas complexas pela multiplicidade de fatores que influenciam a resposta terapêutica de uma substância exógena, e.g. fármaco, que precisa apresentar elevada eficácia, reflexo das propriedades farmacodinâmicas - aquelas que regem as interações responsáveis pelo reconhecimento molecular do fármaco pelo biorreceptor e resultam na resposta terapêutica desejada - e farmacocinéticas - aquelas que governam os fatores de absorção, distribuição, metabolismo e eliminação do fármaco na biofase, resultando no perfil de biodisponibilidade.

A abordagem fisiológica, baseada no mecanismo de ação farmacológica pretendida para o novo fármaco, fundamenta-se no prévio conhecimento do processo fisiopatológico e na consequiente eleição do alvo-terapêutico mais adequado e busca o planejamento de novos padrões estruturais, originais, ativos in vivo, candidatos a compostos-protótipos de fármacos ${ }^{26}$.

A heurística deste processo determina, portanto, que quando da eleição prévia do alvo-terapêutico se identifique sua localização celular, e.g. membrânico, transmembrânico ou intracelular, bem como o tipo de intervenção terapêutica que se pretenda realizar, e.g. inibição enzimática, antagonista ou agonista de biorreceptores ${ }^{27}$. A escolha da estratégia de planejamento estrutural a ser adotada para o desenho molecular do novo ligante dependerá do nível de conhecimento estrutural do alvo terapêutico eleito.

Caso seja conhecida a estrutura tridimensional (3D) do alvoeleito e, principalmente, aquela do sítio de reconhecimento molecular, o planejamento molecular de ligante seletivo pode apelar para estratégias baseadas na química computacional ${ }^{28}$. Identificado o novo padrão estrutural, este será sintetizado e avaliado através de bioensaios in vitro que, em caso de sucesso, nos fornecerá um novo ligante do biorreceptor eleito como alvo-terapêutico ${ }^{29}$ Uma vez disponível sinteticamente em estado de pureza adequado, o novo ligante é submetido à etapa de validação do conceito terapêutico à origem da eleição do alvo, compreendendo o emprego de bioensaios farmacológicos, in vivo. Esta etapa é crítica no processo pois, além de validar experimentalmente o conceito terapêutico do alvo eleito, permite identificar as propriedades farmacocinéticas do ligante candidato a novo composto-protótipo. Em caso de sucesso nesta etapa, temos a descoberta de novo composto-protótipo, candidato a fármaco atuando no receptor eleito, o que representa importante resultado na cadeia de inovação em fármacos (Figura 6).

Alternativamente, quando a estrutura do alvo terapêutico não é conhecida $^{30}$, o desenho molecular de novos padrões estruturais do candidato a composto-protótipo desejado (Figura 6) pode ser conduzido a partir do emprego de estratégias de planejamento estrutural da Química Medicinal ${ }^{31}$,e.g. identificação de novos análogos ativos do substrato natural do receptor ou do agonista da enzima eventualmente eleita como alvo-terapêutico. O planejamento molecular racional destes análogos-ativos pode se dar pelo emprego do bioisosterismo ${ }^{20}$, da simplificação molecular ${ }^{32}$, da hibridação molecular ${ }^{33}$, entre outras metodologias de planejamento molecular da Química Medicinal ${ }^{34}$. Uma vez definidos e sintetizados, os novos compostos são ensaiados farmacologicamente, empregandose protocolos in vivo, o que permite a identificação de novos compostos-protótipos de novos fármacos.

Cabe ressaltar que, independente da estratégia adotada para planejamento molecular dos novos padrões estruturais dos candidatos a compostos-protótipos, deve-se, obrigatoriamente, levar em conta todas as possíveis contribuições toxicofóricas das subunidades moleculares presentes na série congênere de compostos planejados, especialmente quanto ao potencial tóxico relacionado ao sistema microssomal do retículo endotelial hepático, responsável por oxidações dependentes do CYP450, essenciais à bioformação de substâncias endógenas e ao correto funcionamento de funções fisiológicas vitais, e.g. hormônios esteróidais ${ }^{35}$. A presença de grupos funcionais eletrofílicos (e.g. grupos funcionais aceptores de Michael, epóxidos, i.e., intermediários-reativos) e sub-unidades estruturais extensamente coplanares deve ser considerada como atributo de potencial hepatoe citotoxicidade, respectivamente, devendo ser, portanto, evitada. Procedendo-se dessa forma reduz-se o risco de serem identificadas, posteriormente, propriedades tóxicas indesejáveis que condenem o composto-protótipo descoberto.

Uma vez descoberto o novo composto-protótipo, a etapa seguinte na cadeia de inovação em fármacos é sua otimização. Nesta etapa, devem ser identificadas as distintas contribuições farmacofóricas de todas as subunidades estruturais, de maneira a orientar as modificações moleculares a serem introduzidas na estrutura do composto-protótipo ampliando a diversidade estrutural deste padrão molecular, o que é significativamente relevante para elaboração de pedidos de proteção intelectual desta descoberta.

$\mathrm{Na}$ etapa de otimização do composto-protótipo, o emprego de técnicas de química computacional aplicadas ao desenho de fármacos são particularmente úteis, e.g. QSAR, CoMFA, CoMSIA ${ }^{36}$, entre outras $^{37,38}$. Ademais, a construção de modelos topográficos $3 \mathrm{D}$ do sítio de reconhecimento molecular do biorreceptor ${ }^{39}$ orienta, ao menos teoricamente, as modificações moleculares necessárias à otimização das propriedades farmacodinâmicas do protótipo.

A etapa de otimização do composto-protótipo deve ser realizada simultaneamente àquela da investigação das propriedades de biodisponibilidade do protótipo-eleito, de maneira a instruir sobre a necessidade de se introduzirem novas modificações moleculares em sua estrutura visando otimizar, também, as propriedades farmacocinéticas. Este procedimento antecipa, por sua vez, preciosas informações para a etapa futura de desenvolvimento galênico do composto-protótipo descoberto.

A realização dos ensaios de toxidez subaguda, compreendendo a determinação da dose letal média e sua relação com a dose efetiva média, i.e. $\mathrm{LD}_{50}$ e $\mathrm{ED}_{50}$, respectivamente, deve ser feita, simultaneamente nesta etapa, de maneira a se estabelecer o provável índice terapêutico do novo candidato a fármaco. Ensaios subseqüentes de toxidez aguda, determinando-se histologicamente eventuais efeitos sobre os principais órgãos, i.e. fígado, pulmão e sistema nervoso central, além dos efeitos sobre a concentração plasmática dos principais agentes bioquímicos, e.g. uréia, glicose, atividade transaminase, entre outros, devem ser realizados anteriormente aos estudos pré-clínicos, em mais de uma espécie de animais de laboratório.

Neste estágio do processo, caso o novo composto-protótipo descoberto tenha superado todas as etapas consecutivas da cadeia de inovação, temos a descoberta de uma nova entidade molecular $(\mathrm{NME} \text { 's })^{40}$ que representa, na prática, a etapa imediatamente anterior àquela dos ensaios pré-clínicos, onde será aferido o potencial de emprego seguro do candidato a novo fármaco, propriamente dito.

Cabe ressaltar que a condução adequada destas etapas, consecutivas e simultâneas, na velocidade que o processo de inovação exige, irá demandar quantidades crescentes do composto-protótipo para que se realizem, com celeridade, os ensaios pré-clínicos. A Figura 7 ilustra a quantidade relativa de substância pura necessária ao cumprimento de cada etapa deste processo. Por ex., para que se realizem os bioensaios iniciais in vitro sobre determinado alvoterapêutico, se necessitará não mais que 1-10 $\mu \mathrm{g}$ de substância. Identificando-se uma atividade com potência adequada nesta etapa do processo precisar-se-á de 1-10 mg do composto, sob forma pura, para início dos ensaios in vivo. Logrando-se a descoberta de um 


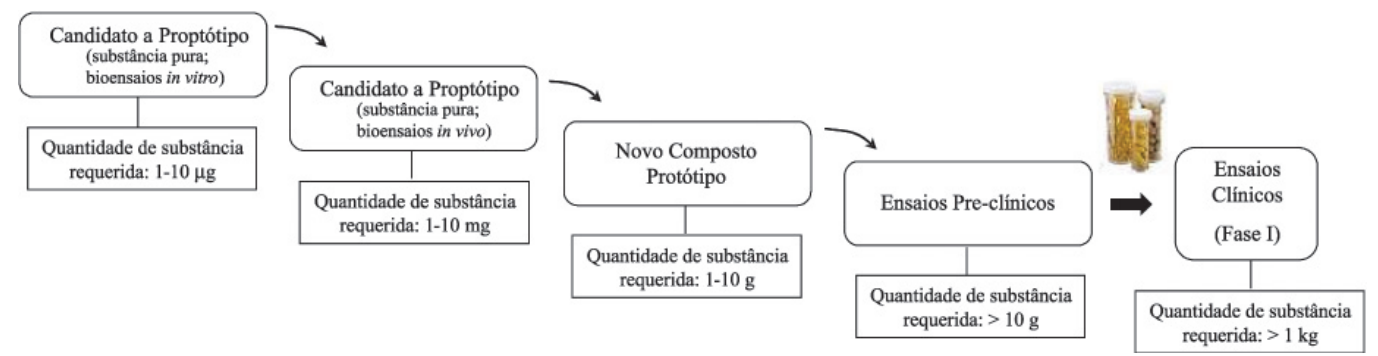

Figura 7. Escala de quantidades necessárias de substância pura para realização de bioensaios nas diferentes etapas hierárquicas da cadeia de inovação em fármacos

novo composto-protótipo serão necessários, desta feita, de 1 a $10 \mathrm{~g}$ da substância para que complete os bioensaios in vivo, visando confirmar o provável mecanismo de ação e avaliar o potencial tóxico do novo composto, geralmente empregando-se diferentes rotas de administração de maneira a adquirir, precocemente, informações sobre sua biodisponibilidade. Para realização dos ensaios pré-clínicos, indispensáveis ao avanço na cadeia, serão necessárias quantidades superiores a 100 g de substância. Para início dos ensaios clínicos, geralmente, se precisará de mais de $1 \mathrm{~kg}$ de composto. Esta demanda crescente em quantidades de composto-protótipo deve estimular os estudos, simultâneos, de "scale-up" do processo de obtenção da substância e de métodos de detecção de eventuais impurezas.

\section{O valor das inovações farmacêuticas}

Inúmeros artigos recentes destacam a existência de uma crise de criatividade no setor farmacêutico, relacionada com a diminuição constante do número de NEQ's efetivamente inovadoras, descobertas nos laboratórios de pesquisa das indústrias farmacêuticas ${ }^{41}$. Especialistas do setor industrial farmacêutico consideram que a capa- cidade inovadora da IF que faz pesquisa de novos fármacos não está compatível com a densidade de investimentos realizados em PD\&I. Por ex., dados da associação representativa da IF norte-americana $(\mathrm{PhRMA})^{42}$ estimam que foram investidos em PD\&I na IF mundial, em 2003, ca. US\$ 33 bilhões, valor recorde, enquanto que o número de NEQ's inovadoras não aumentou proporcionalmente.

Esta realidade atual parece sugerir, como nova motivação estratégica para a IF que tem na inovação radical sua maior estratégia de competição mercadológica, a busca por moléculas inovadoras, capazes de representarem autênticas NEQ's, candidatas a novos fármacos, quiçá bilionários, através de novas parcerias com laboratórios de pesquisa universitários, localizados não mais apenas em seus países sedes.

Cabe registrar que o faturamento de uma IF multinacional, geralmente, se consolida com base em poucos fármacos de elevada capacidade em vendas, denominados "blockbusters"43. A Figura 8 ilustra os dez principais fármacos, em vendas, em 2004, quando o mercado farmacêutico mundial atingiu o montante de US\$ 505 bilhões em faturamento. Observa-se que os cinco primeiros fármacos - atorvastatina, simvastatina, clopidogrel, amlodipina e olanzepina, respectivamente - são responsáveis por expressiva fatia do merca-

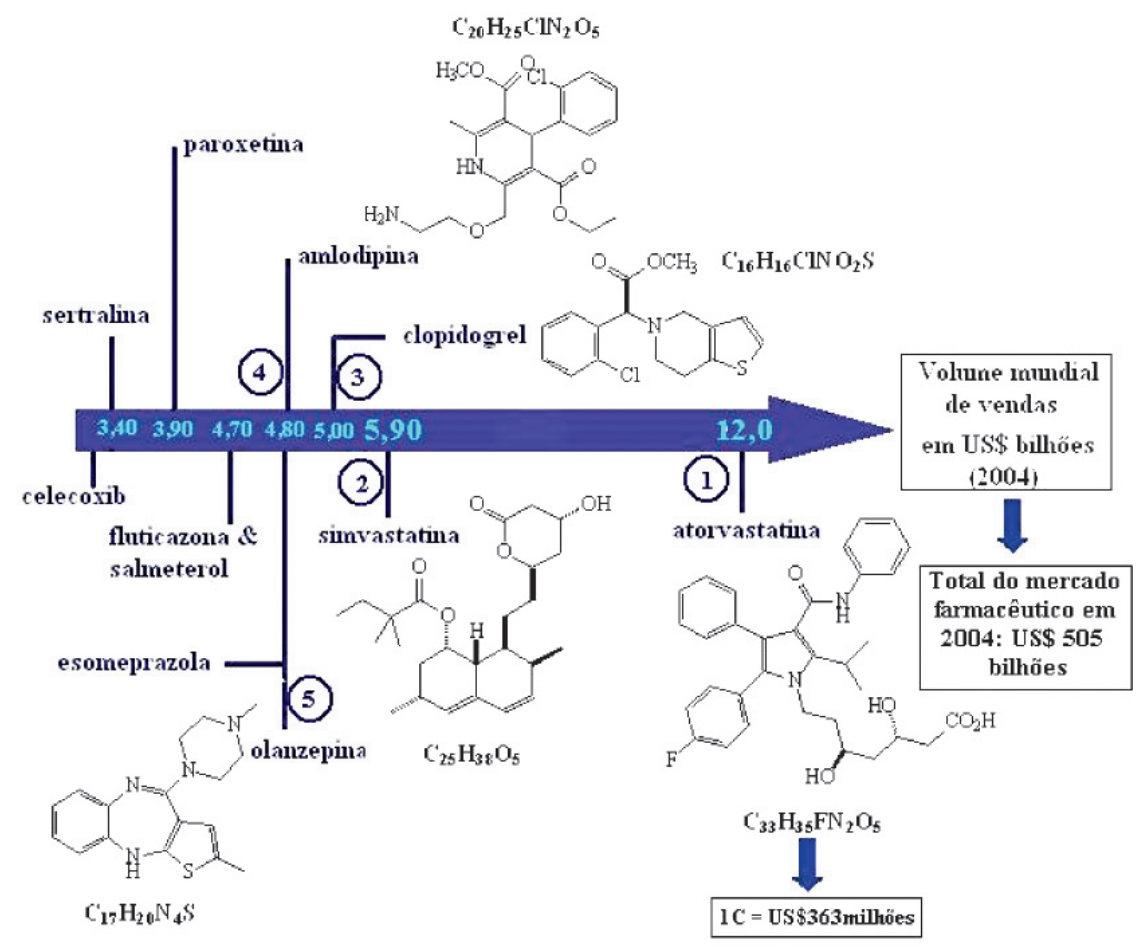

Figura 8. Dez principais fármacos em vendas (2004) com as estruturas dos cinco primeiros: atorvastatina (1), simvastatina (2), clopidogrel (3), amlodipina (4) e olanzepina (5) 
do, tendo faturado $c a$. US $\$ 32,5$ bilhões em 2004, o que corresponde a $c a$. $6,5 \%$ do mercado total. Os três primeiros fármacos deste "ranking" podem ser considerados como medicamentos recomendados para tratamento de doenças cardiovasculares, enquanto que os dois restantes são fármacos neuroativos. $\mathrm{O}$ primeiro e segundo da lista são, fármacos indicados como anti-lipêmicos, atuando como inibidores enzimáticos no mesmo alvo-terapêutico, capazes de totalizarem, sozinhos, US\$ 17,9 bilhões em vendas naquele ano, sendo que o líder - atorvastatina - atingiu a marca histórica dos US\$ 12 bilhões, rompendo a barreira dos US\$ 10 bilhões de vendas para um único fármaco, em um único ano. Em termos da diversidade estrutural destes cinco fármacos, líderes do mercado mundial, constata-se a presença de apenas sete elementos químicos distintos (e.g. C, H, O, N, S, Cl e F), sendo todos compostos de origem sintética, policíclicos, com unidades carbocíclicas e heterocíclicas, totalizando 111 átomos de carbono e possuindo apenas 10 centros estereogênicos, sendo que 7 estão presentes na mesma molécula (e.g. simvastatina $)^{44}$. À exceção da simvastatina, todos os outros fármacos dentre os cinco primeiros do mercado farmacêutico mundial possuem, no mínimo, um anel heterocíclico e contêm apenas sete outros grupos funcionais orgânicos diferentes em suas estruturas.

Gargalos da cadeia de inovação em fármacos

A Figura 9 ilustra, ainda que de forma resumida, a complexidade da cadeia de inovação em fármacos, que se inicia, como mencionado, com a eleição do alvo-terapêutico indo até à descoberta do novo composto-protótipo, da NEQ, autêntico candidato a novo fármaco, destacando sua principal característica, a natureza multidisciplinar desta cadeia, que abrange, além das Ciências Farmacêuticas, outras disciplinas das áreas de Saúde e Exatas.

Identificam-se, facilmente, os principais gargalos quantitativos desta cadeia no que se refere às competências intrínsecas, uti- lizando, por exemplo, os dados referentes aos grupos de pesquisa (GP) cadastrados na Plataforma Lattes do CNPq, e empregando-se palavras-chave relacionadas a Fármacos e Medicamentos ${ }^{45}$. Estes gargalos se situam, em sua ampla maioria, em disciplinas diretamente relacionadas às Ciências Farmacêuticas e em termos quantitativos, havendo nítida carência de GP's atuantes nestas disciplinas, especialmente em Toxicologia e Química Medicinal. Aliás, esta insuficiência é proporcional à atrofia quantitativa, em relação a outras áreas relacionadas aos fármacos, em cursos de Pós-graduação na área da Farmácia no País. Esta atrofia é responsável pelo baixo número de pós-graduados qualificados titulados, insuficiente para dar conta do desafio posto.

\section{Proposta: PROGRAMA NACIONAL DE FÁRMACOS (PRONFAR)}

Neste momento em que se elabora a $2^{\text {a }}$ Conferência Nacional de Ciência, Tecnologia e Inovação em resposta à capacitação do empreendimento científico e tecnológico de inovação brasileiro, é imprescindível que se articulem ações capazes de promoverem, de fato, a capacitação nacional na cadeia produtiva de fármacos. Embora em maio de 2003 tenha sido instalado o Fórum de Competitividade da Cadeia Produtiva Farmacêutica, no âmbito do Ministério do Desenvolvimento, Indústria e Comércio Exterior, composto de cinco grupos de trabalho: Acesso aos Medicamentos, Compras Governamentais e Inclusão Social; Investimentos; Comércio Exterior e Tributação; Regulação e Qualidade e, Tecnologia, as ações promovidas por este Fórum continuam desconhecidas, pois não observaram a transparência desejada e necessária à mobilização dos diversos atores para solução da questão dos Fármacos e Medicamentos. Outrossim, ações descontinuadas e isoladas de diversos agentes do governo, que parecem estar relacionadas com a questão dos Fármacos e Medicamentos pipocam aqui e ali em vários ambientes governamentais. Sem vínculos entre si, estas ações, tímidas,

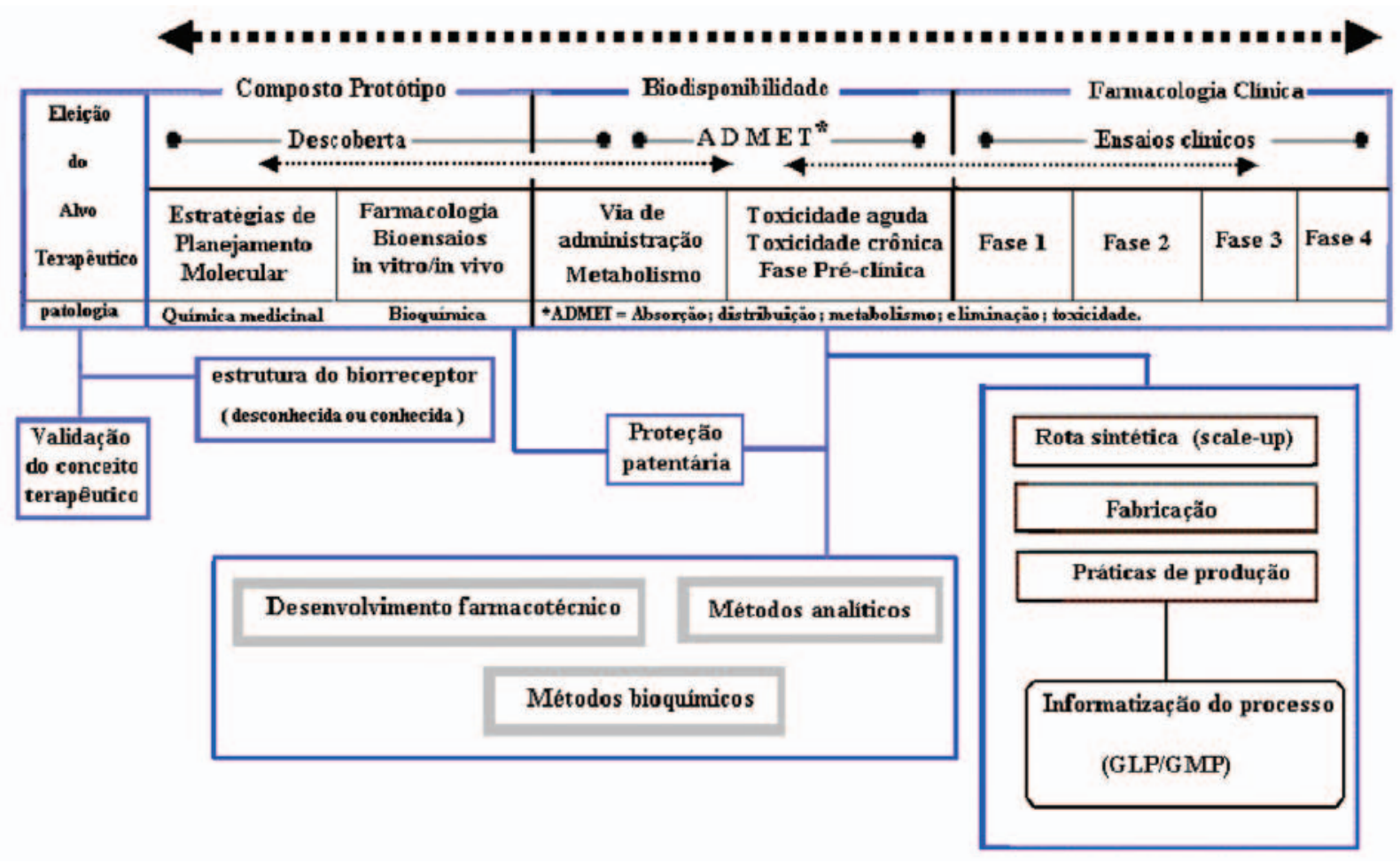

Figura 9. Visão esquemática da Cadeia de Inovação em Fármacos 
inclusive em termos de recursos alocados, resultarão apenas em algumas páginas de relatórios internos, suficientes apenas para justificarem o cumprimento burocrático de posições administrativas ocupadas por gestores alheios à competência técnica necessária a tornarem estas ações ocas em uma política de resultados efetivos, contribuindo para a efetiva construção da cadeia produtiva dos fármacos, com óbvios benefícios à população ${ }^{46}$.

Embora possamos detectar vários documentos públicos, disponíveis nos portais oficiais de distintos órgãos do governo, tratando do diagnóstico das diversas etapas da cadeia produtiva de fármacos carecem, estes mesmos organismos, de ações explícitas que representem, de fato, uma efetiva vontade política em busca de soluções perenes para esta angustiante questão.

A despeito destas iniciativas registradas, que se destacam pela falta de efetividade, defendemos a criação do Programa Nacional de Fármacos, abrangente, de caráter inter-ministerial, coordenado por Comitê Gestor que englobe o atual Fórum e esteja capacitado a tratar de todas as ações necessárias à formulação de estratégias capazes de resultarem em ações que viabilizem a superação das limitações existentes e o atendimento das necessidades identificadas para a solução da questão relativa aos Fármacos e Medicamentos no Brasil, reclame justo da sociedade brasileira, que se relacionam com a formação de recursos humanos qualificados, a capacitação das instituições à realização de pesquisas de forma a viabilizar, também, a inovação radical e incremental, a produção de fármacos genéricos, novos ou não. Promover ações que aproximem, de fato, a Universidade do setor empresarial, através da capacitação e atualização continuada de seus quadros e habilitados a responder, em prazos previamente estabelecidos, aos desafios relativos à construção da independência nacional no setor dos Fármacos e Medicamentos, indispensáveis à assistência farmacêutica da população, nosso primeiro e maior patrimônio.

A Figura 10 sumariza a proposta.

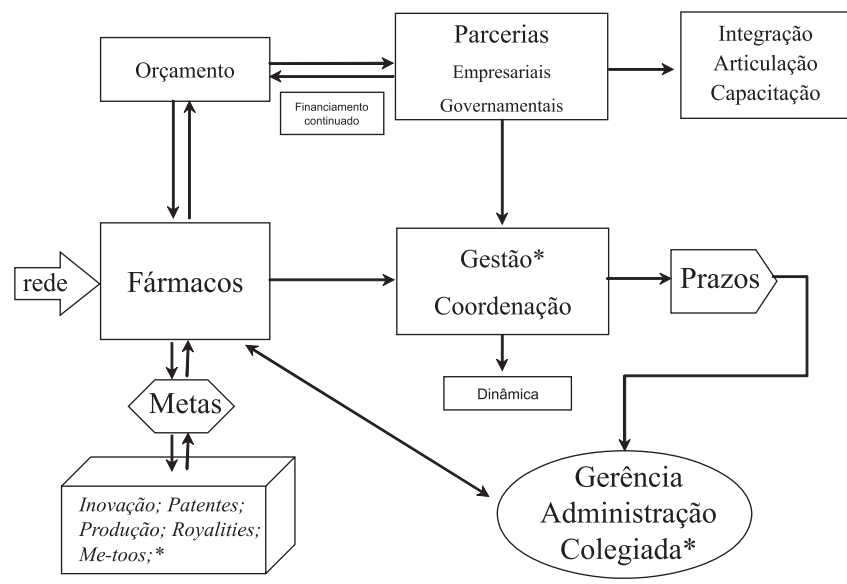

Figura 10. Proposta esquematizada da criação do Programa Nacional de Fármacos (PRONFAR)

\section{CONSIDERAÇÕES FINAIS}

Há de ser salientado que o processo de inovação em fármacos e medicamentos é eminentemente exigente quanto ao nível de qualificação dos profissionais, geralmente pós-graduados, envolvi$\operatorname{dos}^{24,47,48}$. Esta realidade explica o elevado índice de qualificação da força de trabalho empregada nos laboratórios de pesquisa das grandes empresas farmacêuticas que descobrem fármacos ${ }^{49}$, inexistentes no País, que abriga estas competências nas universidades públicas dos sistemas federal ou estadual.
Em termos da capacidade inovadora do setor industrial farmacêutico internacional, é digno de registro o momento crítico que atravessa, obtendo resultados inversamente proporcionais aos recursos investidos em $\mathrm{P} \& \mathrm{D}^{50}$. Inúmeros especialistas registram, em diversas publicações conceituadas, esta crise de criatividade que vivem as empresas farmacêuticas que descobrem fármacos ${ }^{21}$. Por outro lado, há relatos elogiosos na literatura internacional sobre a notável capacidade produtiva científica do País ${ }^{51}$, que têm se destacado na liderança da América Latina como sendo a comunidade científica mais produtiva da região, atingindo $c a$. $1,5 \%$ da produção do conhecimento científico novo mundial, em todas as áreas, inclusive aquelas relacionadas à inovação em fármacos e medicamentos ${ }^{50}$.

A se considerar o atual nível de capacitação científica do País, inclusive em áreas de ponta do conhecimento científico em Ciências da Saúde, Biológicas, Farmacêuticas e Químicas - relacionadas aos fármacos e medicamentos - principal característica da inovação farmacêutica - constata-se condições extremamente propícias e favoráveis à inovação em fármacos e medicamentos no Brasil, necessitando apenas de se articularem as competências nacionais disponíveis ${ }^{52}$.

\section{AGRADECIMENTOS}

Ao PRONEX, FAPERJ, CNPq e à FUJB pelo apoio financeiro e bolsas concedidas.

\section{REFERÊNCIAS E NOTAS}

1. Neamati, N.; Barchi Jr., J. J.; Curr. Top. Med. Chem. 2002, 2, 211.

2. McCarthy, I. Em Tackling industrial complexity: the ideas that make a difference; Frizelle, G.; Richards, H., eds.; Institute for Manufacturing of University of Cambridge: Cambridge, 2002, p. 373.

3. Estratégia conhecida pelo termo anglo-americano "serendipity" (sem tradução para a Língua Portuguesa) cunhado em 1754, pelo escritor inglês Horace Walpole.

4. Lax, E.; The Mold in Dr Florey's Coat: The Story of the Penicillin Miracle, Henry Holt and Company: Nova Iorque, 2004.

5. Campbell, S. F.; Clinical Science 2000, 99, 255.

6. Bickel, M. H.; Gesnerus 1988, 45, 67.

7. Cragg, G. M.; Newman, D. J.; Pure Appl. Chem. 2005, 77, 7; Newman, D. J.; Cragg, G. M.; Snader, K. M.; J. Nat. Prod. 2003, 66, 1002.

8. Kingston, D. G. I.; Molinero, A. A.; Rimoldi, J. M.; Prog. Chem. Org. Nat. Prod. 1993, 61, 1.

9. Wani, M. C.; Taylor, H. L.; Wall, M. E.; Coggon, P.; McPhail, A. T.; J. Am. Chem. Soc. 1971, 93, 2325.

10. A partir do conhecimento do esqueleto taxano um segundo fármaco antitumoral foi desenvolvido por Potier e colaboradores. Inter-alia: Guenard, D.; Gueritte-Voegelein, F.; Potier, P.; Acc. Chem. Res. 1993, 26, 160; Nicolaou, K. C.; Guy, R. K; Potier, P.; Scientific American 1996, 94.

11. Cox, B.; Denyer, J. C.; Binnie, A.; Donnelly, M. C.; Evans, B.; Green, D. V.; Lewis, J. A.; Mander, T. H.; Merritt, A. T.; Valler, M. J.; Watson, S. P.; Progr. Med. Chem. 2000, 37, 83.

12. Soudijn, W.; Pharm. Weekblad-Scientific Ed. 1991, 13, 161.

13. IUPAC, recomendações de 1998.

14. diMasi, J. A.; Paquette, C.; Pharmacoeconomics 2004, 22 Suppl. $2,1$.

15. Bradshaw, J.; Brittain, R. T.; Clitherow, J. W.; Daly, M. J.; Jack, D.; Price, B. J.; Br. J. Pharmacol. 1979, 66, 464P.

16. Main, B. G.; Tucker, H. Em The Role of Organic Chemistry in Drug Design; Ganellin, C. R.; Roberts, S. M., eds; Academic Press: Nova Iorque, 1993, p. 93.

17. Reuben, B. G.; Wittcoff, H. A.; Pharmaceutical Chemical in Perspective, Wiley: Nova Iorque, 1989, p. 284.

18. Ganellin, C. R.; Drug Discovery Today 2004, 9, 158.

19. Frishman, W. H.; New Engl. J. Med. 1983, 308, 940.

20. Lima, L. M.; Barreiro, E. J.; Curr. Med. Chem. 2005, 12, 23.

21. Ver ref. 16, p. 69.

22. Ganellin, C. R.; J. Med. Chem. 1981, 24, 913.

23. Ondetti, M. A.; Cushman, D. W. Em Chronicles of Drug Discovery; Bindra, J. S.; Lednicer. D., eds.; Wiley: Nova Iorque, 1982, vol. 2, p. 1.

24. Gassmann, O.; Reepmeyer, G.; van Zedtwitz, M.; Leading Pharmaceutical Innovation Trends and Drivers for Growth in the Pharmaceutical Industry, Springer: Nova Iorque, 2004. 
25. Barreiro, E. J.; Fraga, C. A. M.; Química Medicinal: Razões Moleculares da Ação dos Fármacos, ArtMed Ed.: Porto Alegre, 2001, p. 15.

26. Lindsay, M. A.; Nat. Rev. Drug Discovery 2003, 3, 831.

27. Dickson, M.; Gagcon, J-P.; Nat. Rev. Drug Discovery 2004, 3, 417.

28. A pesquisa de novos candidatos a protótipos nos laboratórios de empresas farmacêuticas que descobrem fármacos ou em "spin-offs", sob contrato, pode empregar técnicas de avaliação de quimiotecas de compostos naturais ou sintéticos, obtidos combinatoriamente, ou não, acoplados aos bioensaios robotizados que propiciam a análise de milhares de amostras de substâncias puras ou em misturas combinatórias. A identificação de novos compostos ativos por estas técnicas, geralmente na escala nM, representa a descoberta de um "hit", que por ser um mero ligante tem que ser validado em ensaios com animais.

29. Para um artigo recente discutindo as conceituações e distinções entre "hit", ligante e composto-protótipo, ver Crossley, R.; Modern Drug Discovery 2002, december, 18.

30. Ganellin, C. R. Em Chronicles of Drug Discovery; Lednicer, D., ed.; Wiley: Nova Iorque, 1990.

31. Ver ref. 25 , p. 163.

32. Para exemplo da utilização desta estratégia no desenho de novos candidatos a protótipos de fármacos no LASSBio, ver Barreiro, E. J.; Quim. Nova 2002, 25, 1172.

33. Para exemplo da utilização desta estratégia no desenho de novos candidatos a protótipos de fármacos no LASSBio, ver Fraga, A. G. M.; Miranda, A. L. P.; Fraga, C. A. M.; Barreiro, E. J.; Eur. J. Pharm. Sci. 2000, 11, 285. Para exemplo da utilização desta estratégia no desenho de novos candidatos a protótipos de fármacos no LASSBio-UFRJ, ver Barreiro, E. J.; Quim. Nova 2002, 25, 1172.

34. Flower, D., ed.; Drug Design: Cutting Edge Approaches (Special Publication), Royal Society of Chemistry: Londres, 2002; Burger, A.; Prog. Drug Res. 1991, 36, 287.

35. Ver ref. 25 , p. 35 .

36. Gund, P.; Maggiora, G.; Snyder, J. P. Em Guidebook on Molecular Modeling in Drug Design; Cohen, N. C., ed.; Academic Press: Nova Iorque, 1996, p. 219.
37. Höltje, H-D. Em The Practice of Medicinal Chemistry; Wermuth, C-G., ed.; $2^{\text {nd }}$ ed.; Academic Press: Nova Iorque, 2003, p. 387.

38. Itai, A.; Mizutani, Y.; Nishibata, Y.; Tomioka, N. Em Guidebook on Molecular Modeling in Drug Design; Cohen, N. C., eds.; Academic Press: Nova Iorque, 1996, p. 93.

39. Barreiro, E. J.; Albuquerque, M. G.; Sant'Anna, C. M. R.; Alencastro, R. B.; Quim. Nova 1997, 29, 300.

40. Um excelente glossário dos principais termos de Química Medicinal, está disponível em http://www.chem.qmw.ac.uk/iupac/medchem/ix.html, acessada em Agosto 2005.

41. Milne Jr., G. M.; Annu. Rep. Med. Chem. 2003, 38, 384.

42. http://www.pharma.com, acessada em Agosto 2005.

43. Zambrowicz, B. P.; Sands, A. T.; Nat. Rev. Drug Discovery 2003, 2, 38

44. Dentre os cinco fármacos considerados a simvastatina é aquele com a estrutura química mais próxima de um produto natural.

45. E.g.: fármaco; química medicinal; química farmacêutica; tecnologia farmacêutica; desenvolvimento farmacotécnico; desenvolvimento galênico; farmacognosia; controle de qualidade de medicamentos; farmacologia; toxicologia; síntese de fármacos; produtos naturais bioativos.

46. Cadeia produtiva é o conjunto de atividades articuladas, progressivamente, partindo dos insumos básicos até o produto final, i.e. medicamento, incluindo sua distribuição e comercialização.

47. Cf. Cohen, F. J.; Nat. Rev. Drug Discovery 2005, 4, 79.

48. Class, S.; $C \& E N$ 2002, $80,39$.

49. Ver em http://www.i-s-b.org/business/pharma.htm, acessada em Agosto 2005.

50. Kennedy, D.; Science 2004, 303, 1717; Kennedy, D.; Science 2004, 303, 1796; Cuthbert, A.; Curr. Opin. Pharmacol. 2004, 4, 487.

51. http://www.capes.gov.br/capes/portal/conteudo/10/EstatisticasPG.htm, acessada em Agosto 2005.

52. Cabe registro o Seminário sobre o Complexo Industrial da Saúde (2003), promovido pelo BNDES. Ver em http://www.bndes.gov.br/conhecimento/ publicacoes/catalogo/s_saude.asp, acessada em Agosto 2005. 